\title{
The Effect of Hydration and Caffeine on Post-Spinal Anesthesia Headache: A Randomized Controlled Study
}

\section{Ozlu ZK ${ }^{1 *}$, Yayla $\mathrm{A}^{1}$, Ozlu I ${ }^{2}$ and Donmez $\mathrm{N}^{3}$}

${ }^{1}$ Department of Surgical Nursing, Faculty of Health Sciences, Atatürk University, Turkey

${ }^{2}$ Ataturk University Medical Faculty Hospital, Turkey

${ }^{3}$ Surgical Nursing, Kahramanmaraş Necip Fazil Hospital, Turkey

*Corresponding author: Ayșegül Yayla, Department of Surgical Nursing, Faculty of Health Sciences, Atatürk University, Erzurum, Turkey, Tel: +90 442231 2364; Email: ayseguul21@ hotmail.com

\section{Research Article \\ Volume 4 Issue 1}

Received Date: January 09, 2020

Published Date: February 10, 2020

DOI: $10.23880 /$ nhij-16000216

\section{Abstract}

Objective: Evaluate the effects of hydration and caffeine, administered of patients who received spinal anesthesia, on postspinal headache.

Methods: Randomized controlled experimental study. The study was carried out in the post-anesthesia care unit and surgery clinics of a City Hospital between November and December 2014. The sample composed of 90 patients who received spinal anesthesia. The patients were assigned into 3 groups based on the order of leaving the operating room by using a randomization check list. Percentage and chi-square test were used to assess the data.

Results: It was found that $23.3 \%$ of the patients in the first group (receiving $3000 \mathrm{cc}$ intravenous fluid), $20.0 \%$ of the patients in the second group (Intravenous $3000 \mathrm{ml}$ fluid $+75 \mathrm{mg}$ ( 4 cups) oral caffeine), and 13.3\% of the patients in the third group (Intravenous $4000 \mathrm{ml}$ fluid) had headaches. Post-Spinal Anesthesia Headache was similar between the groups. But, it was determined that number of the patients with headache in third group was lower. Most of the patients in all three groups specified that their headaches reduced by resting, increased by standing up, did not cover their nucha and shoulder, and increased by movement.

Conclusion: It is concluded that although there was no statistical significance, rate of headache in the hydration group (Third group) was lower than the other groups. Also it was determined that administration of excess fluid after spinal anesthesia reduced the level of post-spinal headache but it could not prevent its development.

Keywords: Spinal anesthesia; Post-spinal anesthesia headache; Different fluid administrations 
Abbreviations: CSF: Cerebrospinal Fluid; PSHA: Post Spinal Headache; VCS: Verbal Category Scale.

\section{Introduction}

Spinal anesthesia is an anesthesia method in which local anesthetics are injected in subarachnoid space and all the senses in the lower part of the body are blocked by administering small volume of local anesthetics [1]. This method has superiorities in many operation and patient groups compared to general anesthesia. It has numerous advantages such as continuation of the spontaneous ventilation, awaking of patient and maintenance of protective reflexes such as swallowing and coughing during operation, as well as early mobilization, minimal pulmonary complications, continuation of analgesia and shortened length of hospital stay [2,3].

Spinal anesthesia has a rapid effect and is easy to apply, which makes spinal anesthesia a preferable method [4-6]. Nowadays, this technique is commonly used for thoracic surgeries (T4) in general operations, gynecology, orthopedics and urology [7-9]. Despite various merits, spinal anesthesia has some complications such as nausea, vomiting, neck stiffness, double vision, tinnitus, photophobia, hearing loss, neck pain, and headache [10-13]. A previous study Bedirli N, et al. reported that the prevalence of post-spinal anesthesia headache was $25 \%$. On the other hand, in the study of Zeger, et al. (2012), they found that the prevalence of postoperative headaches was about 30\% [14].

After dura puncture made due to any injury in dura, headache may develop. Dural tear may result in potentially high quantity of CSF (Cerebrospinal fluid) leak. After a dural tear, the decrease in the CSF pressure due to CSF leaking associated with the dural defect and subsequent cerebral venous dilatation leads to PSHA (post spinal headache) $[1,15,16]$. PSHA worsens within 15 minutes after sitting down and standing up following any lumbar puncture and relieves within 15 minutes after lying positioning. 90\% of PSHA may develop three days after the procedure and $66 \%$ may develop during the first 48 hours [13]. Headache is typically bilateral frontal or retro orbital, occipital and progress to nucha. Unless some cases receive treatment for headache, the surgical repair may be required [16]. PSHA likely leads to significant morbidity and is a complication that requires a serious treatment. PSHA is usually a self-limiting process [17]. PSHA may cause other problems in addition to the symptoms of headache. Treatment of PSHA may bring along delayed hospital discharges and hospital readmissions and this increases health expenses [18]. Symptoms of the condition can be self-limiting but in untreated or undiagnosed cases, PSHA can result in significant associated comorbidity, including death [19]. Therefore, it is important to take measures against the complications that may develop after spinal anesthesia, and minimize or early notice the potential complications [20].

Patients with PSHA should not suffer needlessly. There are numerous conservative treatment options for PSHA such as hydration, caffeine, and analgesics or 4 other pharmacologic approaches, each of which has varying degrees of efficacy [19]. In the literature; lying position, oral or intravenous fluid administration, analgesics and caffeine are stated as the conservative treatment to prevent postspinal headache. It is reported that hydration and caffeine affect prevention and reduction of PSHA by increasing the CSF production [21,22]. Caffeine is a central nervous system stimulant that produces cerebral vasoconstriction among other properties and causes a transient reduction in cerebral blood flow. Yet in the study conducted by Camann, et al. [23] in Boston, they determined that application of oral caffeine decreased level of PSHA in patients undergoing surgeries under spinal anesthesia. However, although many methods are suggested for prevention of PSHA, which method is more efficient today is still controversial matter and therefore it is required to conduct further randomized controlled trials on this subject [1]. In the light of this information; in this study it is aimed to compare the effect of fluid and caffeine administrations on PSHA in the patients.

The hypotheses of the study

$\mathrm{H}_{1}=$ Hydration and Caffeine administration has no effect in preventing headache in patients under spinal anesthesia.

$\mathrm{H}_{2}=$ Caffeine administration has an effect in preventing headache in patients under spinal anesthesia.

$\mathrm{H}_{3}=$ Hydration has an effect in preventing headache in patients under spinal anesthesia.

\section{Method}

The study was carried out in the post-anesthesia care unit and surgery clinics of a City Hospital between November and December 2014.

The population of the study consisted of patients who received spinal anesthesia at Hospital. The sample of the study consisted of a total of ninety patients (30 patients in $3000 \mathrm{cc}$ hydration group, 30 patients in $3000 \mathrm{cc}$ hydration+ caffeine group, and 30 patients in $4000 \mathrm{cc}$ hydration group) who required urology or general surgery, received spinal anesthesia at Hospital between November and December 2014 , and agreed to participate in the study. The patients who received spinal anesthesia were assigned into three groups in a randomized and controlled manner based on order of leaving the operating room in the early postoperative period. This procedure was continued until the targeted number was reached. The patients who agreed the spinal anesthesia, 
and did not have any contraindication for spinal anesthesia, hemorrhage and coagulopathy, cardiovascular diseases, neurological deficits, chronic headache (like migraine), congestive heart failure or chronic renal failure were included in the study. 4 patients who developed tachyarrhythmia during the study were excluded from the study.

A patient information form was used to gather the data of the study.

\section{Patient Information Form}

Developed by the researchers upon related literature review, the questionnaire had 21 questions related to the patients' descriptive characteristics [24,25]. This form was filled by the researcher conducting a face-to-face interview with the patients. The questions on age, gender, educational status, height, weight, BMI, previous surgeries, number of interventions for spinal anesthesia, previous spinal anesthesia administration, educational period of the person applying spinal anesthesia, interval of spinal anesthesia, state of moving the back during spinal anesthesia, presence of headache, onset time of headache, reduction in headache by resting, diagnosis of headache, pain relieving method, factors increasing headache, status of the pain to cover nucha and shoulder, and increasing of headache by movement were asked to the patients.

\section{Verbal Category Scale (VCS)}

This scale, also called as Simple Descriptive Scale, aims to assess the pain level and is based on selection of the most appropriate term defining the pain status by the patient. The pain level ranges from mild to unbearable level. The patient/person is asked to select the option appropriate for the condition. Melzack and Torgerson used "mild", "discomforting", "distressing", "horrible", "excruciating" words to define the pain level. The scale was used due to its advantages such as being easily applicable and having a simple classification [26].

In the study, in addition to the verbal pain scale, a questionnaire prepared according to the Post-Spinal Headache classification of "International Headache Society" was also administered to identify whether the headaches of the patients were post spinal headaches or not $[27,28]$.

The subarachnoid space was inserted at L3-L4, L4L5 space by using a 27 quincke needle after skin of the participant was cleaned in the sitting position in accordance with the rules of antisepsis and covered. $3 \mathrm{ml}(15 \mathrm{mg})$ of $0.5 \%$ hyperbaric bupivacaine was injected to the intrathecal space. Since most of the patients were older than 34 years in the study, this needle type was used. Intravenous vascular access was established to the patients before administering premedication. $0.9 \% \mathrm{NaCl}$ solution was given to all the patients including the control group: It was started to be administered in the intraoperative period just before spinal anesthesia. After the patients were taken to the operating room, it was noticed to administer the fluids in the same amount to the patients. $0.9 \% \mathrm{NaCl}$ isotonic fluid was given to all of the patients in group 3. Routinely, fluid of $3000 \mathrm{ml}$ is administered to the patients. Since in the literature it is stated that intravenous fluids are administered as $6 \mathrm{ml} /$ $\mathrm{kg} / \mathrm{h}$ at medium-sized surgeries, such administration was implemented to the patients [29]. According to randomization chart, $500 \mathrm{ml}$ of $0.9 \% \mathrm{NaCl}$ (its rate suitable for the patients by considering their hemodynamic parameters) was administered to the patients in Group 130 minutes before spinal anesthesia. Afterwards, standard monitorization was performed in all of the patients in both groups taken into the operating room and infusion of $0.9 \% \mathrm{NaCl}$ was started. After they came to the clinic, infusion of $0.9 \% \mathrm{NaCl}$ was continued. Totally $3000 \mathrm{ml}$ of $0.9 \% \mathrm{NaCl}$ was administered. Additionally the patients in second group drank 4 cups of Instant Coffee, each of which contained $75 \mathrm{mg}$ of caffeine, in the clinic 8 hours after the surgery $\left(75^{*} 4=300 \mathrm{mg}\right)$. In the literature, it is suggested to administer $300 \mathrm{mg}$ of caffeine daily in order for caffeine to be effective in headache [17]. $500 \mathrm{ml}$ of $0.9 \%$ $\mathrm{NaCl}$ (its rate suitable for the patients by considering their hemodynamic parameters) was intravenously administered to the patients in Group 3 just before spinal anesthesia. Then, standard monitorization was performed in all of the patients in both groups taken into the operating room and infusion of $0.9 \% \mathrm{NaCl}$ was started. After they came to the clinic, infusion of $0.9 \% \mathrm{NaCl}$ was continued. Totally $4000 \mathrm{ml}$ of $0.9 \% \mathrm{NaCl}$ was administered. All of the patients in three groups were informed not to drink other fluids containing caffeine such as tea and coke in particular.

The patients were informed about the procedure; the patients gave their verbal consent before the participation. Firstly, the patients were verbally asked whether they would participate in the study or not. Written consents of those who verbally agreed to participate in the study were also obtained. The patients included in the study were divided into three groups as randomized controlled based on order of leaving the operating room and specified amounts of fluid and caffeine were administered to the groups.

The study was submitted to the an university, Faculty of Health Sciences Ethics Committee. Approval of Ethics Committee was obtained for the study. Questionnaire-related permission was received from the an University, Faculty of Health Sciences. Questionnaire Committee assessed the relevance of questions in the patient information form. Written official permissions were received from Hospital, where the study was conducted. Written consents of the 
patients who verbally agreed to participate in the study were also obtained. Necessary explanations about the aim of the study, administration method and results planned to be obtained were made to the patients included in the study and their verbal consent was taken. Written consents of the patients whose verbal consent was received were also obtained. The ethical principle of "Informed Consent" was realized by explaining the aim of the study to the patients before data collection in order to protect rights of the patients included in the study; the ethical principle of "Protection of Confidentiality and Privacy" by stating that the acquired data would be kept confidential; and the ethical principle of "Respect for Autonomy" by including volunteer patients in the study. In the study, the ethical principle of "Respect for Human Dignity" was taken into consideration. Those who wanted to participate in the study were included in the study. The Declaration of Helsinki regarding human rights was obeyed during the study due to necessity of protection of individual rights. Non-disclosure of identity information of the patients was ethically taken into consideration. The patients were informed about the risk and benefits of the study through consent form.

\section{Dependent Variables}

Post Spinal Headache.

\section{Independent Variables}

Hydration and caffeine, practitioner anesthetist, number of spinal anesthesia-related interventions.

\section{Statistical Analysis}

Statistical Package for the Social Science (SPSS Inc, Chicago, Illinois, USA) version 16.0 was used for the analysis. The difference between the mean scores in terms of age, height, weight, and BMI was evaluated by using two independent samples $t$ tests. Chi square test was used to compare the characteristics between the groups.

This study was a randomized controlled study. The patients who received spinal anesthesia were given number based on order of leaving the operating room. The research and patients were not blinded. Since it is impossible to determine list of the patients, a randomization list prepared by a computer program was used in order to avoid bias while assigning the patients into the groups. Since there was no participant list, the letters " $\mathrm{A}$ "," $\mathrm{B}$ ", and " $\mathrm{C}$ " written by the computer program against numbers were matched with the groups. In the list, the letter " $\mathrm{A}$ " represented the patients to be included in the control group, the letter " $B$ " represented the patients to be included in the caffeine group and the letter " $\mathrm{C}$ " represented the patients to be included in the hydration group. The patients undergoing surgeries under spinal anesthesia were assigned into the groups based on their order in the randomization list. For example, the first operated participant was represented with the letter " $A$ " and included in the control group. The second operated participant was included in the group B; whereas, the third operated participant was included in the group C. The patients were assigned into 3 groups based on the order of leaving the operating room by using a randomization check list $[30,31]$. The fact that $16.7 \%$ of the sample were female is one of limitations of the study.

\section{Results}

When the descriptive characteristics of the groups were compared (Table 1), it was determined that majority of the patients were in age group of 34 years and over, male and primary school graduates in all three groups and there was no statistically significant difference between the groups in terms of age, height, weight, and mean BMI. They were similar in terms of their descriptive characteristics $(\mathrm{p}>0.05)$.

\begin{tabular}{|c|c|c|c|c|c|c|c|}
\hline \multirow{2}{*}{ Characteristics } & \multicolumn{2}{|c|}{ Group I } & \multicolumn{2}{|c|}{ Group II } & \multicolumn{2}{|c|}{ Group III } & \multirow{2}{*}{ Test and $p$ value } \\
\hline & $\mathbf{n}$ & $\%$ & $\mathbf{n}$ & $\%$ & $\mathbf{n}$ & $\%$ & \\
\hline \multicolumn{8}{|c|}{ Age } \\
\hline $18-25$ years & 7 & 23.3 & 8 & 26.7 & 9 & 30 & \multirow{3}{*}{$\begin{array}{c}X^{2}=3.31 \\
p>0.05\end{array}$} \\
\hline 26-33 years & 4 & 13.3 & 4 & 13.3 & 8 & 20 & \\
\hline 34 years and $\uparrow$ & 19 & 63.4 & 18 & 60 & 15 & 50 & \\
\hline \multicolumn{8}{|c|}{ Gender } \\
\hline Female & 5 & 16.7 & 8 & 26.7 & 4 & 13.3 & \multirow{2}{*}{$\begin{array}{c}X^{2}=1.88 \\
p>0.05\end{array}$} \\
\hline Male & 25 & 83.3 & 22 & 73.3 & 26 & 86.7 & \\
\hline \multicolumn{8}{|c|}{ Education } \\
\hline
\end{tabular}




\begin{tabular}{|c|c|c|c|c|c|c|c|}
\hline Primary education & 15 & 50 & 11 & 36.7 & 15 & 50 & \multirow{3}{*}{$\begin{aligned} X^{2} & =3.31 \\
p & >0.05\end{aligned}$} \\
\hline Secondary education & 8 & 26.7 & 6 & 20 & 5 & 16.7 & \\
\hline High school and $\uparrow$ & 7 & 23.3 & 13 & 43.3 & 10 & 33.3 & \\
\hline Age [Mean (SD)] & \multicolumn{2}{|c|}{$40.40 \pm 16.34$} & \multicolumn{2}{|c|}{$40.66 \pm 17.35$} & \multicolumn{2}{|c|}{$38.60 \pm 18.47$} & $\begin{array}{l}F=0.12 \\
p>0.05\end{array}$ \\
\hline Height [Mean (SD)] & \multicolumn{2}{|c|}{$1.70 \pm 0.06$} & \multicolumn{2}{|c|}{$1.71 \pm 0.07$} & \multicolumn{2}{|c|}{$1.72 \pm 0.06$} & $\begin{array}{l}F=0.55 \\
p>0.05\end{array}$ \\
\hline Weight [Mean (SD)] & \multicolumn{2}{|c|}{$75.70 \pm 8.35$} & \multicolumn{2}{|c|}{$75.30 \pm 11.44$} & \multicolumn{2}{|c|}{$74.80 \pm 12.41$} & $\begin{array}{l}\mathrm{F}=0.05 \\
\mathrm{p}>0.05\end{array}$ \\
\hline BMI & \multicolumn{2}{|c|}{$25.96 \pm 2.86$} & \multicolumn{2}{|c|}{$25.68 \pm 3.15$} & \multicolumn{2}{|c|}{$25.10 \pm 3.94$} & $\begin{array}{l}F=0.53 \\
p>0.05\end{array}$ \\
\hline
\end{tabular}

Table 1: Comparison of the descriptive characteristics of the groups.

Table 2 shows comparison of the spinal anesthesiarelated characteristics of the groups. In all three groups, it was determined that most of the patients were administered with this intervention once, anesthesia was administered from L4-
L5 space. When the spinal anesthesia-related characteristics of the groups were compared, it was determined that there was no statistically significant difference was present between 3 groups were homogeneous ( $p>0.05)$.

\begin{tabular}{|c|c|c|c|c|c|c|c|}
\hline \multirow{2}{*}{ Characteristics } & \multicolumn{2}{|c|}{ Group I } & \multicolumn{2}{|c|}{ Group II } & \multicolumn{2}{|c|}{ Group III } & \multirow{2}{*}{ Test and $p$ value } \\
\hline & $\mathbf{n}$ & $\%$ & $\mathbf{N}$ & $\%$ & $\mathbf{n}$ & $\%$ & \\
\hline \multicolumn{8}{|c|}{ Surgery } \\
\hline General Surgery & 25 & 83.3 & 24 & 80 & 26 & 86.7 & $\mathrm{X}^{2}=0.48$ \\
\hline Urology & 5 & 16.7 & 6 & 20 & 4 & 13.3 & $p>0.05$ \\
\hline \multicolumn{8}{|c|}{ Spinal anesthesia interval } \\
\hline L3-4 & 2 & 6.7 & - & - & 2 & 6.7 & $\mathrm{X}^{2}=2.09$ \\
\hline L4-5 & 28 & 93.3 & 30 & 100 & 28 & 93.3 & $p>0.05$ \\
\hline
\end{tabular}

Table 2: Comparison of characteristics of the groups regarding spinal anesthesia.

Table 3 shows comparison of the headache-related characteristics of the groups. It was determined that headache was present in $23.3 \%$ of the patients in first group (receiving $3000 \mathrm{cc}$ fluid), $20.0 \%$ of the patients in second group (receiving $3000 \mathrm{cc}$ fluid and caffeine), and 13.3\% of the patients in third group (4000 cc fluid). Additionally, it was found that headache developed after 12.01-18.00 hours in $71.4 \%$ of the patients in first group and after 18.01 and $\uparrow$ in $50.0 \%$ of the patients in second and third groups. Headache of $14.3 \%$ of the patients in first group was mild and headache of $28.6 \%$ was excruciating; headache of $33.3 \%$ of the patients in second group was mild and headache of $16.7 \%$ was excruciating and headache of $75.0 \%$ of the patients in third group was mild and all the patients did not have an excruciating pain. It was observed that headache of $57.1 \%$ of the patients in first group was permanent; headache of $50.0 \%$ of the patients in second group was intermittent, and headache of $75.0 \%$ of the patients in third group was temporary. Most of the patients in all three groups specified that their headaches reduced by resting, increased by standing up, did not cover their nucha and shoulder, and increased by movement. When the headacherelated characteristics of the groups were compared, it was determined that there was no statistically significant difference between the groups ( $p>0.05)$.

\begin{tabular}{|c|c|c|c|c|c|c|c|}
\hline \multirow{2}{*}{ Characteristics } & \multicolumn{2}{|c|}{ Group I } & \multicolumn{2}{c|}{ Group II } & \multicolumn{2}{c|}{ Group III } & \multirow{2}{*}{ Test and p value } \\
\cline { 2 - 7 } & $\mathbf{n}$ & $\mathbf{0}$ & $\mathbf{n}$ & $\mathbf{\%}$ & $\mathbf{n}$ & $\mathbf{\%}$ & \multicolumn{2}{|c|}{$\mathrm{X}^{2}=1.01$} \\
$\mathrm{p}>0.05$
\end{tabular}

Ozlu ZK, et al. The Effect of Hydration and Caffeine on Post-Spinal Anesthesia Headache: A Randomized Controlled Study. Nurs Health Care Int J 2020, 4(1): 000216. 


\begin{tabular}{|c|c|c|c|c|c|c|c|}
\hline After 8-12 hours & 1 & 14.3 & 2 & 33.3 & 1 & 25 & \multirow{3}{*}{$\begin{aligned} X^{2} & =2.37 \\
p & >0.05\end{aligned}$} \\
\hline After 12:01-18 hours & 5 & 71.4 & 1 & 16.7 & 1 & 25 & \\
\hline After 18:01 hours and $\uparrow$ & 1 & 14.3 & 3 & 50 & 2 & 50 & \\
\hline \multicolumn{8}{|c|}{ Reduction in headache through resting } \\
\hline Reducing & 5 & 71.4 & 4 & 66.7 & 3 & 75 & \multirow{2}{*}{$\begin{array}{l}X^{2}=1.27 \\
p>0.05\end{array}$} \\
\hline Not reducing & 2 & 28.6 & 2 & 33.3 & 1 & 25 & \\
\hline \multicolumn{8}{|c|}{ Level of headache } \\
\hline Mild & 1 & 14.3 & 2 & 33.3 & 3 & 75 & \multirow{5}{*}{$\begin{array}{l}X^{2}=5.31 \\
p>0.05\end{array}$} \\
\hline Disturbing & 2 & 28.6 & 1 & 16.7 & 1 & 25 & \\
\hline Severe & 1 & 14.3 & 1 & 16.7 & - & - & \\
\hline Very severe & 1 & 14.3 & 1 & 16.7 & - & - & \\
\hline Intolerable & 2 & 28.6 & 1 & 16.7 & - & - & \\
\hline \multicolumn{8}{|c|}{ Diagnosis of headache } \\
\hline $\begin{array}{l}\text { Permanent (it is continuous for a } \\
\text { specific time) }\end{array}$ & 4 & 57.1 & 2 & 33.3 & 1 & 25 & \multirow{3}{*}{$\begin{aligned} \mathrm{X}^{2} & =8.94 \\
\mathrm{p} & >0.05\end{aligned}$} \\
\hline Intermittent & 3 & 42.9 & 3 & 50 & - & - & \\
\hline Temporary & - & - & 1 & 16.7 & 3 & 75 & \\
\hline \multicolumn{8}{|c|}{ Pain relieving method } \\
\hline Resting & 2 & 28.6 & 1 & 16.7 & 2 & 50 & \multirow{3}{*}{$\begin{array}{l}X^{2}=6.49 \\
p>0.05\end{array}$} \\
\hline Sleeping & 1 & 14.3 & 4 & 66.8 & 2 & 50 & \\
\hline Resting+painkiller & 4 & 57.1 & 1 & 16.7 & - & & \\
\hline \multicolumn{8}{|c|}{ Factors increasing pain } \\
\hline Standing up & 6 & 85.7 & 4 & 66.7 & 3 & 75 & \multirow{2}{*}{$\begin{aligned} X^{2} & =0.65 \\
p & >0.05\end{aligned}$} \\
\hline Noise & 1 & 14.3 & 2 & 33.3 & 1 & 25 & \\
\hline \multicolumn{8}{|c|}{ Nucha and shoulder involvement of pain } \\
\hline Involved & 2 & 28.6 & 2 & 33.3 & - & - & \multirow{2}{*}{$\begin{array}{l}X^{2}=1.65 \\
p>0.05\end{array}$} \\
\hline Not involved & 5 & 71.4 & 4 & 66.7 & 4 & 100 & \\
\hline \multicolumn{8}{|c|}{ Increasing of pain by movement } \\
\hline Increasing & 7 & 100 & 4 & 66.7 & 3 & 75 & \multirow{2}{*}{$\begin{array}{l}X^{2}=2.66 \\
p>0.05\end{array}$} \\
\hline Not increasing & - & - & 2 & 33.3 & 1 & 25 & \\
\hline
\end{tabular}

Table 3: Comparison of the characteristics of the groups regarding headache.

When the symptoms accompanying post-spinal headache in the patients were compared (Table 4), it was observed that there was neck stiffness in 4 patients in First group, 1 participant in Second group and 2 patients in Third group; hyperacusia occurred in 3 patients in First group, 4 patients in Second group, and 2 patients in Third group; tinnitus was present in 1 patient in Second group and 1 patient in Third group; photophobia was present in 5 patients in First group, 3 patients in Second group, and 1 participant in Third group; and nausea developed in 2 patients in First group, 2 patients in Second group, and 1 participant in Third group. When the symptoms accompanying post-spinal headache in the groups were compared, it was determined that there was no statistically significant difference between the groups $(\mathrm{p}>0.05)$. 


\begin{tabular}{|c|c|c|c|c|c|c|c|}
\hline \multirow{2}{*}{ Characteristics } & \multicolumn{2}{|c|}{ Group I } & \multicolumn{2}{|c|}{ Group II } & \multicolumn{2}{|c|}{ Group III } & \multirow{2}{*}{ Test and $p$ value } \\
\hline & $\mathbf{n}$ & $\%$ & $\mathbf{n}$ & $\%$ & $\mathbf{n}$ & $\%$ & \\
\hline \multicolumn{8}{|c|}{ Development of neck stiffness } \\
\hline Yes & 4 & 57.1 & 1 & 16.7 & 2 & 50 & \multirow{2}{*}{$\begin{array}{c}X^{2}=2.35 \\
p>0.05\end{array}$} \\
\hline No & 3 & 42.9 & 5 & 83.3 & 2 & 50 & \\
\hline \multicolumn{8}{|c|}{ Development of Hyperacusia } \\
\hline Yes & 3 & 42.9 & 4 & 66.7 & 2 & 50 & \multirow{2}{*}{$\begin{array}{c}X^{2}=0.75 \\
p>0.05\end{array}$} \\
\hline No & 4 & 57.1 & 2 & 33.3 & 2 & 50 & \\
\hline \multicolumn{8}{|c|}{ Development of Tinnitus } \\
\hline Yes & - & - & 1 & 16.7 & 1 & 25 & \multirow{2}{*}{$\begin{array}{c}X^{2}=1.74 \\
p>0.05\end{array}$} \\
\hline No & 7 & 100 & 5 & 83.3 & 3 & 75 & \\
\hline \multicolumn{8}{|c|}{ Development of Photophobia } \\
\hline Yes & 5 & 71.4 & 3 & 50 & 1 & 25 & \multirow{2}{*}{$\begin{array}{c}X^{2}=2.23 \\
p>0.05\end{array}$} \\
\hline No & 2 & 28.6 & 3 & 50 & 3 & 75 & \\
\hline \multicolumn{8}{|c|}{ Development of Nausea } \\
\hline Yes & 2 & 28.6 & 2 & 33.3 & 1 & 25 & \multirow{2}{*}{$\begin{array}{c}X^{2}=0.08 \\
p>0.05\end{array}$} \\
\hline No & 5 & 71.4 & 4 & 66.7 & 3 & 75 & \\
\hline
\end{tabular}

Table 4: Comparison of the Symptoms accompanying post spinal headache in the patients.

\section{Discussion}

Post-spinal headache is one of the most frequent and known complications of spinalanesthesiain the postoperative period since the early years of the administration. In this study, the effect of fluid and caffeine administration on postspinal headache in patients, who received spinal anesthesia, was examined and the results were discussed.

When the descriptive characteristics and spinal anesthesia-related characteristics of the patients in experimental and control groups were examined, it was found that there was no statistically significant difference between the groups Tables $1 \& 2$. This result showed that the groups were homogeneous and had similar characteristics.

When the headache-related characteristics of the groups were compared, it was observed that even though there was no statistically significant difference between the groups, there were lower number of patients having headache in Third group to which hydration was administrated, the level of headache was mild, headache was temporary, less patients had pain while standing up, headache did not cover nucha and shoulder, and less patients had pain increasing by movement (Table 3). PSHA develops due to the intracranial stress on the nerves because of the reduction in intracranial pressure depending on CRF loss. The purpose in the treatment of PSHA is to reduce the symptoms until dura repairs itself. Treatment methods can be applied in two ways as conservative methods and invasive methods [27]. In PSHA treatment, it is aimed to increase CRF production by hydration administration involved among conservative methods [32]. Dehydration causes reduction in CRF production. Rate of CRF production increases by oral or intravenous hydration and thus recovery is obtained in the clinical picture [33]. In the study of Bezow, bed rest, hydration, and analgesics were used in the patients developing PSHA and it was determined that PSHA had a recovery of $50 \%$ in the first 4 days [34]. It was determined that administration of excess fluid in the patients reduced the pain felt in PSHA but could not prevent its development. It is thought that the main reason of PSHA can be hypovolemia in CRF associated with the continuous leaking of CRF and headache may develop when approximately $10 \%$ of the total CRF volume is lost [35]. In a study, when the VAS scores of the cases with post- spinal anesthesia headache were compared, no significant difference was found between the groups [36]. In this study, it can be considered that the pain intensity was felt milder because there was an increase in the CRF volume via the fluids administered but they could not completely prevent development of the pain.

In the study conducted by Masoudifar, et al. to examine the effect of dexamethasone + oral caffeine + acetaminophen after spinal anesthesia on intensity and frequency of postural headache, they specified that frequency and duration of postspinal headache reduced in the group of dexamethasone+ oral caffeine + acetaminophen compared to the placebo group but the development of headache could not be prevented 
[37]. In another study, it was determined that caffeine administered in addition to intravenous treatment reduced VAS scores [38]. Again in the studies, it was observed that headache relieved in $75 \%$ of the patients, to whom single dose of caffeine was intravenously administered $[39,40]$. In the study conducted by Camann, et al. with 40 patients after delivery, they examined the efficiency of oral caffeine administration in PSHA treatment. $300 \mathrm{mg}$ caffeine capsule was given to the patients and it was determined that VAS values at 4 th hour reduced at the rate of $300 \%$ compared to the placebo group. However, they observed that there was no significant difference between two groups at 24th hour [41]. Again in the study of Esmaoğlu, it was observed that there was no difference in the groups, to whom paracetamol and caffeine were administered after spinal anesthesia, in terms of development of post-spinal headache [42]. In another study, it was specified that oral caffeine reduced the intensity of post-spinal headache [43]. Similar to such studies, in the present study it could be thought that the level of headache was lower in the group, to which caffeine was administered, than the control group.

In a study, it was observed that back movement of the participant during administration of spinal anesthesia had no effect on post-spinal headache [44]. In the study of Choi, et al. they reviewed 13 publications ( 5 randomized controlled studies, 2 cohort studies, 6 case series) and specified that PSHA started on 1st-7th days after the administration and lasted for 1-7 days [45]. In another study, it was determined that PSHA started at postoperative 2 nd hour at the earliest and on the 2 nd postoperative day at the latest; headache completely relieved averagely on 5th day between 1-30 days by virtue of the treatment [38]. In another study, headache which was thought to be induced by spinal anesthesia, developed in 41 of patients (17\%). No headache was observed in 120 (89\%) of postpartum 133 patients, to whom prophylactic fluid was administered, and headache developed in $13(11 \%)$ patients. No headache was observed in $74(73 \%)$ of postpartum 102 patients, to whom prophylactic intravenous infusion was not applied, and headache occurred in $28(27 \%)$ patients. It was shown that hydration was 2.5 times protective in the development of PSHA in postpartum patients [46]. In the study of Vanzetta, et al. they observed that pain of the patients with PSHA relieved by bed rest and intravenous fluid treatment [47]. In this study, it could be thought that hydration administered to the patients caused the pain level of the patients to reduce and the pain to relieve with rest and without using painkiller since it increased CSF production.

In the study, it was determined that there were neck stiffness in 7 patients, hyperacusia in 9 patients, tinnitus in 2 patients, photophobia in 9 patients and nausea in 5 patients in total number of patients with PSHA (Table 4). PSHA diagnostic criteria depending on low CRF pressure are defined by "The İnternational Classification of Headache Disorders". Among the criteria used in this classification, at least one of the symptoms such as neck stiffness, tinnitus, hearing loss, photophobia, and nausea should accompany to the headache that worsens within 15 minutes after standing up or sitting down or recovers within 15 minutes after bed resting $[29,30,32,48]$. In the study of Schmittner, et al. they reported that at least one of accompanying symptoms such as nausea, tinnitus, hearing loss, and neck stiffness should be present in the diagnosis of headache [49]. In this study, hyperacusia and photophobia were mostly observed among the symptoms accompanying PSHA in patients. In a study inspecting the accompanying symptoms after spinal anesthesia, it was determined that nausea was present in $60 \%$ of the patients, vomiting in $24 \%$, neck stiffness in $43 \%$, symptoms related to vision in $13 \%$, and symptoms related to hearing in $12 \%$ [50]. In the study of Özcan, et al. it was observed that nausea-vomiting (54\%) and tinnitus (32\%) were present among the symptoms accompanying PSHA in the patients [51]. In the study of Kurckowski, it was specified that the most frequent accompanying symptoms of PSHA were photophobia, nausea-vomiting, tinnitus, diplopia, and dizziness [24]. The result of this study is similar to the results of Kurckowski's study.

\section{Conclusion}

As a result of the study, it is concluded that although there was no statistical significance, rate of headache in the hydration group (Third group) was lower than the other groups. Also it was determined that administration of excess fluid after spinal anesthesia reduced the level of postspinal headache but it could not prevent its development. In accordance with this result, the hypothesis $\mathrm{H}_{0}$ "hydration and caffeine have no effect in development of post-spinal anesthesia headache" was confirmed.

According to these results, it can be recommended to include hydration administration in order to reduce the level of pain felt in PSHA and to repeat randomized controlled studies with larger sample groups. As a result of the study it can be recommended to administer fluid by increasing its amount in order to reduce development of PSHA and also to repeat such randomized controlled studies in patients groups including female patients.

\section{References}

1. Doğru S, Kaya Z, Yllmaz Doğru H (2012) Complications of Spinal Anaesthesia. Journal Of Contemporary Medicine 2(2): 127-134.

2. Albright G, Forster R (1993) Spinal analgesia-physiolgic effects. In: Collins VJ (Ed.), Principles of anesthesiology. $3^{\text {rd }}$ (Edn.), Philedelphia: Lea \& Febiger, pp: 1445-1570. 
3. Atkinson RS (1993) Spinal analgesia. In: Atkinson RS, et al. (Eds.), Lee's synopsis of anaesthesia $11^{\text {th }}$ (Edn.), Oxford: Buttenvort-Heinemann International Edition, pp: 691-719.

4. Kayhan Z (2005) Central blocks. Expanded in Clinical Anesthesia 3. printing. Ankara: Logos Publishing, pp: 552-587.

5. Morgan MM, Murray MJ, Larson CP (2004) In: Tulunay M, et al. Clinical Anesthesiology $3^{\text {rd }}$ (Edn.), Ankara: Solar Bookstore, pp: 253-281.

6. Özyalçın SN (2005) Spinal anesthesia-analgesia applications. Erdine S (Ed.), In Regional Anesthesia. Istanbul: Nobel Medical Bookstores, pp: 159-184.

7. Baig $\mathrm{T}$ (2014) Comparison of 25 Gauge Cutting with Noncutting Needles for Post Dural Puncture Headache in Obstetric Patients. J Anesth Clin Res 5(10): 1-3.

8. Bauset Navarro J, Sanchez Ortuno IM, Gomez Cardenas C, Sanz Monllor A, Cinesi Gomez C, et al. (2014) Iatrogenic after Spinal Puncture Technique. Prevalence Study of Headache and Associated Factors. Rev Neurol 58(5): 193-198.

9. Brull R, Macfarlane A, Chan V (2015) Spinal, Epidural, and Cauddal Anesthesia. In: Miller RD EL, et al. (Eds.), Miller's Anesthesia. $8^{\text {th }}$ (Edn.), Philadelphia: Elsevier, pp: 1684-1716.

10. Agerson AN, Scavone BM (2012) Prophylactic Epidural Blood Patch after Unintentional Dural Puncture for the Prevention of Postdural Puncture Headache in Parturients. Anesth Analg 115(1): 133-136.

11. Sachs A, Smiley R (2014) Post-dural puncture headache: The Worst Common Complication in Obstetric Anesthesia. Semin in perinatol 38(6): 386-394.

12. Stendell L, Fomsgaard JS, Olsen KS (2012) There is Room for Improvement in the Prevention and Treatment of Headache after Lumbar Puncture. Dan Med J 59(7): A4483.

13. Arevalo Rodriguez I, Ciapponi A, Roqué i Figuls M, Muñoz L, Bonfill Cosp X (2016) Posture and fluids for preventing post-dural puncture headache. Cochrane Database of Systematic Reviews (3): 1-51.

14. Zeger W, Younggren B, Smith L (2012) Comparison of Cosyntropin Versus Caffeine for Post-Dural Puncture Headaches: A Randomized Double-Blind Trial. World J Emerg Med 3(3): 182-185.

15. Spinal WK, Epidural, Caudal Blocks (2002) In: Morgan
GE, et al. (Eds.), Clinical Anesthesiology $3^{\text {rd }}$ (Edn.) TheMcGraw-Hill Companies, New York, pp: 253-282.

16. Organ GE, Murray MJ (2008) Within regional anesthesia: Pain Treatment, Spinal, Epidural and Caudal Blocks. In: Tulunay M, Clinical Anesthesiology, $4^{\text {th }}$ (Edn.), Istanbul, Güneș Publishing House.

17. Jayaraman A. Post Dural Puncture Headache, pp: 33-35.

18. Apfel CC, Saxena A, Cakmakkaya OS, Gaiser R, George E, et al. (2010) Prevention of postdural puncture headache after accidental dural puncture: A quantitative systematic review. BJA 105(3): 255-263.

19. Velasquez J (2015) Tracking And Management Of PostDural Puncture Headache. A Doctoral Project Doctor Of Nursing Practice.

20. Akça Ay F (2007) Preoperative PreparationPostoperative Care and Follow-up. In: Akça Ay F (ed.), Basic Nursing Concepts, Principles, Practices, $1^{\text {st }}(e d n$.$) ,$ Istanbul, Istanbul Medical Publishing, pp: 393-406.

21. DiGiovanni AJ, Wahle WM (1972) Epidural injection of autologous blood for postlumbar-puncture headache. II. Additional clinical experiences and laboratory investigation. Anesth Analg 51(2): 226-232.

22. Ostheimer GW PR, Shnider SM (1974) Epidural blood patch for postlumbarpuncture headache. Anesthesiology 41(3): 307-308.

23. Camann WR, Murray RS, Mushlin PS, Lambert DH (1990) Effects of oral caffeine on postdural puncture headache. A double-blind, placebo-controlled trial. Anesth Analg 70(2): 181-184.

24. Kuczkowski KM (2004) Post-Dural Puncture Headache In The Obsetric Patient: An Old Problem New Solutions. Minerva Anestesiol 70(12): 823-830.

25. Culhacı ÖS (2015) Evaluation of the Effect of Head and Neck Immobilization of Health Sciences Institute on the Headache After Spinal Anesthesia.

26. Aslan F, Öntürk Z (2014) Pain Measurement And Evaluation. Inside: Aslan Fe. Pain Nature and Control, $2^{\text {nd }}(\mathrm{edn}$.), Ankara, Academician Bookstore, pp: 82-83.

27. Tapar H, Kaya ZSM (2013) Headache After Dura Puncture. Contemporary Medicine Journal 3: 62-66.

28. (2004) International Headache Society Headache Classificaion Subcommittee, International Classification of Headache Disorders, Cephalalgia 24: 7. 
29. (2011) Intravenous fluid infusion. http://www.megep. meb.gov.tr/mte_program_ modul/moduller_pdf. Eriş. Tar. 04.03.2017.

30. Shin YS, Lim NY, Yun SC, Park KO (2009) A randomised controlled trial of the effects of cryotherapy on pain, Eyelid Oedema and Facial Ecchymosis After Craniotomy. Journal of Clinical Nursing 18 (21): 3029-3036.

31. (2017) Research randomizer.

32. Brian V Reamy (2009) Post-Epidural Headache: How Late Can It Occur. J Am Board Fam Med 22(2): 202-205.

33. Ghaleb A, Khorasani A, Mangar D (2012) Post-Dural Puncture Headache. Int J Gen Med 5: 45- 51.

34. Bezow D, Ashina S, Lipton R (2010) Post-Dural Puncture Headache: Part Il - Prevention, Management And Prognosis. Headache 50(9): 1482-1498.

35. Bedirli N, Akkaya T (2010) Postspinal Headache. Journal of Anesthesia 18: 135-140.

36. Onuk S (2011) Complications that may develop during and after spinal anesthesia and investigation of seasonal variation of monitored parameters.

37. Masoudifar M, Aghadavoudi O, Adib S (2016) Effect of Venous Dexamethasone, Oral Caffeine and Acetaminophen on Relative Frequency and Intensity of Postdural Puncture Headache after Spinal Anesthesia. Adv Biomed Res 5: 66.

38. Bozdemir E (2009) Post Dural Headache And Our Treatment Experience Thesis Supervisor.

39. Sechzer P, Abel L (1978) Post-Spinal Anesthesia Headache Treated With Caffeine. Evalution With Demand Method. Part I Curr Ther Res 24: 307-312.

40. Sechzer P (1979) Post-Spinal Anesthesia Headache Treated With Caffeine. Part Iı: Intracranial Vascular Distension, A Key Factor. Curr Ther Res 26: 440-448.

41. Camann WR, Murray RS, Mushlin PS, Lambert DH (1990) Effects of Oral Caffeine on Postdural Puncture Headache: A Double-Blind, Placebo-Controlled Trial. Anesth Analg 70(2): 181-184.
42. Esmaoglu A, Akpinar H, Ugur F (2005) Oral Multidose Caffeine-Paracetamol Combination İs Not Effective For The Prophylaxis of Postdural Puncture Headache. Clinical Trial 17(1): 58-61.

43. Camann WR, Murray RS, Mushlin PS, Lambert DH (1990) Effects Of Oral Caffeine On Postdural Puncture Headache. A Double-Blind, Placebo-Controlled Trial. Anesth Analg 70(2): 181-184.

44. Akdemir M (2010) Factors Related to Post Spinal Headaches and Incidence in the Obstetric Patient Group After Cesarean Operations Under Spinal Anesthesia (Supervisor-Haktan Karaman).

45. Choi PT, Galinski SE, Takeuchi L, Lucas S, Tamayo C, et al. (2003) PDPH is a Common Complication of Neuraxial Blockade in Parturients: A Meta-Analysis of Obstetrical Studies. Can J Anaesth 50(5): 460-469.

46. Zuspan F (1960) Treatment Of Postpartum Postspinal Headache. Obstetrics And Gynaecology 16: 21-26.

47. Vanzetta M, Mezoon B (2005) The Patients' Care after Lumbar Puncture: Hydration and Bed Rest? Assist Inferm Ric 24(1): 25-27.

48. Güneş A, Çevik Y, Karlı N, Sığırlı D (2012) A Study on the Reasons Affecting the Prognosis of Post Lumber Pouch Headache. Journal of Uludağ University Faculty of Medicine 38(3): 161-166.

49. Schmittner MD, Urban N, Janke A, Weiss C, Bussen DG, et al. (2011) Influence of the Pre-Operative Time In Upright Sitting Position and the Needle Type on the Incidence of Post-Dural Puncture Headache (Pdph) İn Patients Receiving A Spinal Saddle Block for Anorectal Surgery. Int J Colorectal Dis 26(1): 97-102.

50. Lybecker H, Djernes M, Schmidt J (1995) Postdural Puncture Headache (PDPH): Onset, Duration, Severity, and Associated Symptoms. An Analysis of 75 Consecutive Patients With PDPH. Acta Anaesthesiol Scand 39(5): 605-612.

51. Özcan Hİ (2012) Investigation of Postspinal Headache Incidence and Predisposing Factors in Patients Undergoing Spinal Anesthesia. 